\title{
Risk Factors Determining the Outcome of 2-12 Months Age Group Infants Hospitalized With Severe Pneumonia
}

\author{
Uddin $\mathrm{KMF}^{1}$, Jahan $\mathrm{N}^{2}$, Mannan $\mathrm{MA}^{3}$, Ferdousi $\mathrm{SA}^{4}$, Farhana $\mathrm{T}^{5}$, Akhter $\mathrm{S}^{6}$, Alam R
}

\begin{abstract}
Pneumonia is one of the leading causes of morbidity and mortality in under fives throughout the world, particularly in developing countries. A case control study was carried out in Bangabandhu Memorial Hospital, University of Science and Technology during the period of January to July 2006. 192 hospitalized infants of 2-12 months age group with World Health Organization $(W H O)$ defined severe pneumonia with radiological confirmation were enrolled in the study, while controls were normal infant of same age group attending EPI center for vaccination. The children were managed using a standard protocol, factors were examined by univariate logistic regression analyasis. The factors whose odds ratio were significantly below $25 \%$ and considered as medically important were included in multivariate logistic regression analysis. Out of 192 children, 136(70.8\%) were male, 56(29.2\%) were female, 2-6 months old infants were 120(62.5\%), >6 -12 months infants were $72(37.5 \%)$, malnutrition were present in 155 ( $80.72 \%), \quad 145(75.5 \%)$ lived in slum area, 66(33.7\%) were treated by quack, $63 \%$ were completely immunized and $3(10.5 \%)$ died. On multivariate analysis the following risk factors were found significant i.e. malnutrition, indoor smoke resulting from burning wood and manure used as fuel, non immunization, poor economy, poor housing. Significant risk factors for mortality in severe pneumonia are associated with $3 r d$ degree malnutrition and congenital abnormality of heart with Downs syndrome. Malnutrition, indoor smoke, non-immunization, poor economy, poor housing, and smoking in bed room are important risk
\end{abstract}

1. Dr. KM Furkan Uddin MBBS Lecturer, Department of Biochemistry Holly Family Red Crescent Medical College, Dhaka

2. Corresponding Author:

Dr. Nasim Jahan MBBS, FCPS

Assistant professor, Department of Neonatology

Ad-din Medical College, Dhaka

E-mail: njahan.jesy@Gmail.com

3. Dr. Md. Abdul Mannan MBBS, FCPS

Assistant professor, Department of Neonatology

Ad-din Medical College, Dhaka

4. Lt. Col (Dr) Shormin Ara Ferdousi MBBS, FCPS Associate Professor, Pediatrics Combined Military Hospital, Momenshahi, Bangladesh

5. Dr. Tashmin Farhana MBBS Indoor Medical Officer, Department of Neonatology Ad-din Medical College Hospital, Dhaka

6. Dr. Shirin Akhter MBBS Indoor Medical Officer, Department of Neonatology Ad-din Medical College Hospital, Dhaka

7. Dr. Rubaiyat Alam MBBS Indoor Medical Officer, Department of Cardiology Bangabandhu Sheikh Mujib Medical University, Dhaka factors associated significantly with severe pneumonia and fatal outcome was associated with 3rd degree malnutrition.

Key wards: Pneumonia, malnutrition, indoor smoke, nonimmunization

\section{Introduction}

According to a UNICEF-World Health Organization (WHO) report from 2006, over 2 million children die from pneumonia each year, accounting for almost one in five under-5 deaths world wide ${ }^{1}$. Of these deaths, two thirds occur during infancy and more than $90 \%$ occur in the developing countries ${ }^{2}$. It is estimated that more than 150 million episodes of pneumonia occur every year among children under five in developing countries, accounting for more than 95 per cent of all new cases worldwide. Between 11 million and 20 million children with pneumonia will require hospitalization, and more than 2 million will die from the disease. It is also important to note that incidence of pneumonia among children decreases with age ${ }^{3}$.

Total area of Bangladesh is $147570 \mathrm{~km}^{2}$, population about 160000 thousands, children under 5 years are $14707^{4}$. Annual no. of birth 3401 thousands, annual no. of under 5 death 330 thousand and under 5 mortality rate 48 per thousand live birth, rank 61 and infant mortality rate (IMR) is 38 per thousand live birth ${ }^{5}$. The present world population is approximately 6.44 billion, one third being under the age of 15 years, 616 million are under 5, 14\% live in developed countries and remaining $86 \%$ in developing countries, over half $(56 \%)$ live in Asia and about $22 \%$ in south Asia. Annual no. of birth in the world approximately 231748 thousand, in developing countries 119157 thousand and in south Asia 37053 thousand ${ }^{5}$. Of them more than 10 million deaths in each year worldwide of children younger than 5 years, especially in infancy, most from preventable causes and almost all in poor countries. Six countries account for $50 \%$ of worldwide deaths and 42 countries for $90 \%$, about $41 \%$ of child death occur in sub- Sahara Africa and another $34 \%$ in south Asia. The cause of death differs substantially from one country to another, and highlights the need to expand understanding of child health epidemiology at a country level rather than geopolitical region. Other key issue include the importance of under nutrition as an underlying cause of child deaths associated with infectious diseases, the effects of multiple concurrent illness, and recognition that pneumonia and diarrhea remain the diseases that are most often associated with child deaths. Distribution of cause of death globally were attributed to neonatal (29-36\%), to pneumonia (14-24\%), to diarrhea (14-30\%), to malaria (6$13 \%)$, to measles $(1-9 \%)$, to other causes ( $9 \%)$ and fewer that $1 \%$ to unknown cause and malnutrition was associated with $53 \%$ of all under 5 death $^{6}$.

World Health Organization (WHO) estimates causes of death in children younger than five years attribute $19 \%$ deaths to pneumonia, $13 \%$ to diarrhea, $9 \%$ malaria, $5 \%$ to 
measles, $3 \%$ AIDS, $42 \%$ to neonatal causes \& $9 \%$ to miscellaneous, other causes including non-communicable diseases and injuries ${ }^{7}$. Overall among all under five children, possible serious infections $(31 \%)$ and ARI $(21 \%)$ were responsible for most of the deaths. This was followed by prenatal condition (19\%), asphyxia (12\%) \& LBW (7\%), diarrhea $(7 \%)$, malnutrition was associated with $22 \%$ of all under five deaths $s^{4,8}$. One in five children under five reported to have symptom of respiratory illness. Prevalence of ARI is highest in infants $(29.55 \%$ in $6-11 \mathrm{~m})$ in male children $(22 \%)$ in rural areas $(21 \%)$ and have prevalent in Barisal division $(26.7 \%)$ overall, one in five children $(20 \%)$, who had symptom of ARI is taken to a health facility a medically trained provider for treatment ${ }^{4,8}$, they constitute 30 to $50 \%$ pediatric attendance and 10 to $30 \%$ of child admission to hospital. $15.9 \%$ of deaths account for 1-5 years ARI and 58 episodes of ARI/year/child ${ }^{9}$. So hospital based study dealing with severe pneumonia is essential is context to our country.

\section{Materials \& Methods}

It was a case control study conducted in the department of child health Bangladesh Memorial Hospital (BBMH), University of Science and Technology (USTC). All the infants (2-12 months age group) presenting with severe pneumonia (according to ARI).admitted in the department of Pediatrics in between the period of January - July 2006 were included in the study. Total numbers were a sample of 192 patients and 192 controls. Patient with pneumonia with no radiological evidence of pneumonia and presence of associated illness i.e. Typhoid fever, Malaria, Congestive heart failure were excluded from the study. 2-12 months age group infant presenting with fever, cough, difficulty in breathing, Infant who had chest in drawing with radiological evidence of consolidation of pneumonia were included in the study. Inclusion criteria for control were healthy infant
2- 12 months age group who were attend the EPI centre for vaccination in Bangabandhu Memorial Hospital (BBMH), University of Science and technology Chittagong (USTC).

After admission into ward relevant history of each patient from parents was recorded. Risk factors were identified from history and physical examination. Malnutrition was categorized using Gomez Classification. X-ray chest was done in all cases. Routine laboratory test and other relevant investigations were done when necessary and indicated. All the patients were treated by standard ARI case management schedule. But patients who had injection Chloramphenicol or injection Ceftriaxone before admission were continued and separate records were kept.

Data was collected by a preformed semi structured questionnaire. Statistical analysis was done using the package EPI-INFO Version 5. Odds ratio was the parameters used for comparison of the risk of developing severe pneumonia depending on different exposures Chi square and fisher exact test were used as test of significance for some sub group calculations. LOGRES was used for Univariate and Multivariate logistic regression analysis by SPSS window version 7.5.

\section{Results}

The table-1 shows the socio-demographic profile of the patients. Out of 192 children enrolled in the study, 136 $(70.8 \%)$ were male \& $56(29.2 \%)$ were female, 2-6 months old infants were $120(62.5 \%), 72(37.5 \%)$ were $>6$ months old. Young maternal age ( $<18$ years) was $5.7 \% \&>18$ yrs old were $94.3 \%$. Academic status of mother below Secondary School Certificate level was $84.4 \%$ \& above Secondary School Certificate level was $75.5 \%$, Increased birth order $(>2)$ was $35.9 \%,>4$ person sleep in one room in $13.5 \%$. Sibs were suffered from ARI in $27.1 \%$ of cases. Children were lived in slum area in $75.5 \%$.

Table-1: Demographic Profile of the Patients

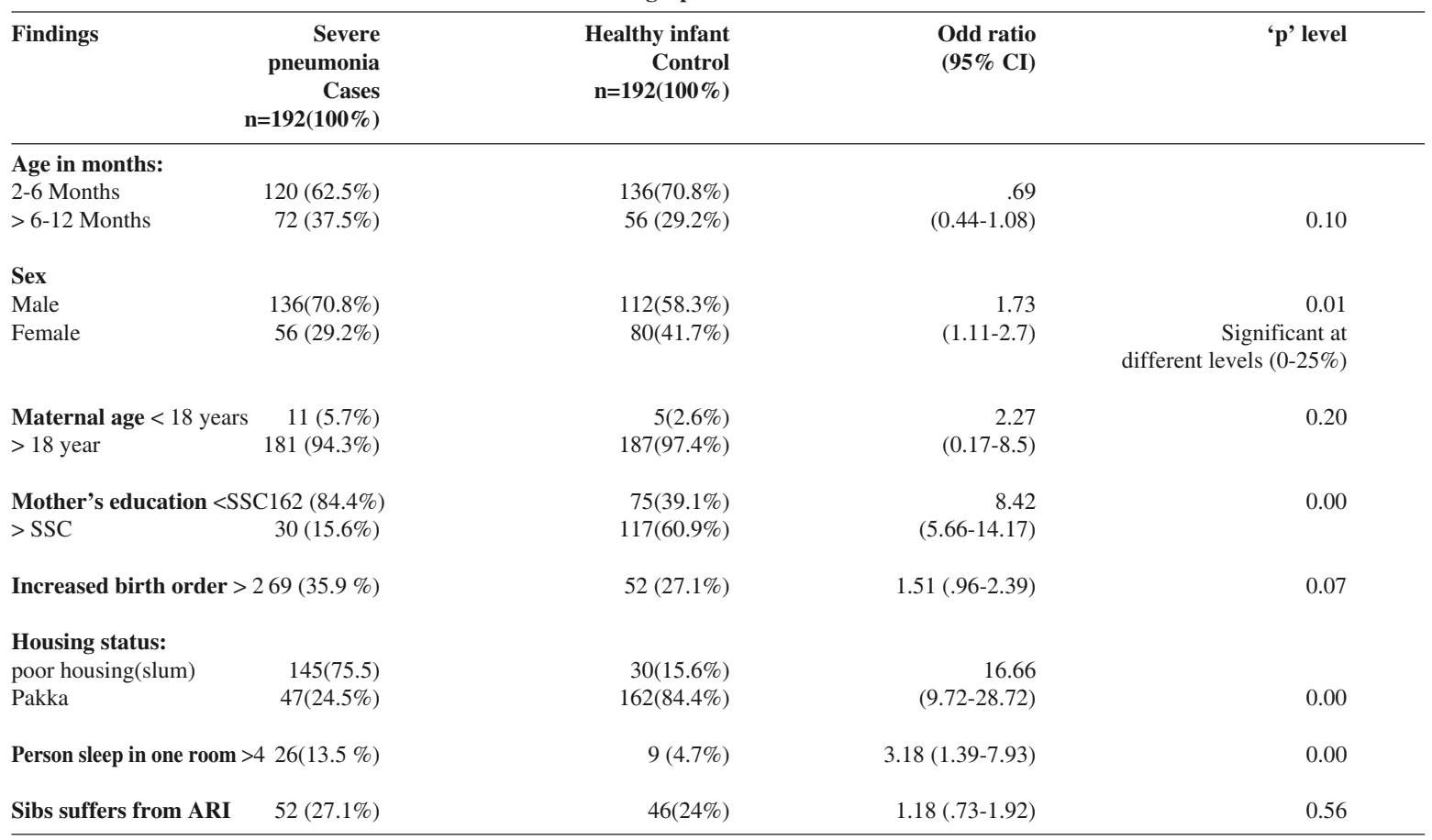


Table 2 shows Malnutrition was present in $80.72 \%$, Seeking qualified doctor's advice was $66.3 \%, 27.1 \%$ Infants didn't take Vit A capsule, Non immunized / incompletely immunized was $37 \%$, 59.9\% infants were on exclusive breast feeding, Cigarette smoking in bedroom was $66.7 \%$ of cases, Indoor smoke was $75.5 \%$. Congenital heart disease was present in $2.1 \%$ of cases.

Table-2: Distribution of severe pneumonic cases and control subjects in relation to nutritional status, vaccination status, feeding, cigarette smoking and congenital anomaly of heart

\begin{tabular}{|c|c|c|c|c|}
\hline Findings & $\begin{array}{r}\begin{array}{r}\text { Severe } \\
\text { pneumonia } \\
\text { Cases }\end{array} \\
\mathrm{n}=192(100 \%)\end{array}$ & $\begin{array}{r}\text { Healthy infant } \\
\text { Control } \\
n=192(100 \%)\end{array}$ & $\begin{array}{l}\text { Odd ratio } \\
(95 \% \mathrm{CI})\end{array}$ & 'p' level \\
\hline $\begin{array}{l}\text { Nutritional Status } \\
\text { (Malnutrition-10, 20, 30) }\end{array}$ & $155(80.72)$ & $56(29.17 \%)$ & $\begin{array}{r}10.17 \\
(6.17-16.85)\end{array}$ & 0.00 \\
\hline Seeking doctor's advice- & & & & \\
\hline Quack/ Homeopathic doctors & $64(33.7 \%)$ & $46(24 \%)$ & 1.59 & \\
\hline Qualified doctors & $128(66.3 \%)$ & $146(76 \%)$ & $(0.99-2.55)$ & 0.05 \\
\hline $\begin{array}{l}\text { Vitamin A intake: } \\
\text { No } \\
\text { Yes }\end{array}$ & $\begin{array}{r}52(27.1) \\
140(72.9 \%)\end{array}$ & $\begin{array}{r}14(7.3) \\
178(92.7 \%)\end{array}$ & $4.72(2.45-9.58)$ & 0.00 \\
\hline $\begin{array}{l}\text { Vaccination status: } \\
\text { Non/incomplete immunization } \\
\text { Complete immunization }\end{array}$ & $\begin{array}{r}71(37 \%) \\
121(63 \%)\end{array}$ & $\begin{array}{r}31(16.1 \%) \\
161(83.9 \%)\end{array}$ & $3.05(1.84-5.12)$ & 0.00 \\
\hline Exclusive breast feeding & $115(59.9 \%)$ & $107(55.7 \%)$ & $1.19(0.78-1.82)$ & 0.47 \\
\hline Cigarette smoking in bedroom & $128(66.7 \%)$ & $65(33.9 \%)$ & $3.91(2.5-6.61)$ & 0.00 \\
\hline $\begin{array}{l}\text { Indoor smoke } \\
\text { Wood or manure }\end{array}$ & $143(74.5 \%)$ & $24(12.5)$ & $\begin{array}{r}20.43 \\
(11.6-36.41)\end{array}$ & 0.00 \\
\hline Congenital abnormalities of heart & $4(2.1 \%)$ & $2(1 \%)$ & $2.02(.29-22.56)$ & 0.68 \\
\hline
\end{tabular}

On multivariate analysis (Table 3 ) the following risk factors were found significant i.e. malnutrition Odd Ratio 6.95 (3.59-13.44; $\mathrm{p}=.00)$; indoor smoke resulting from burning wood and manure used as fuel Odd Ratio 5.04 (2.41-10.53; $\mathrm{p}=.00)$; non immunization Odd Ratio 3.38 (1.52-7.55; $\mathrm{p}=.0029)$; poor housing Odd Ratio 2.64 (1.08-6.51; $\mathrm{p}=.00)$; Cigarette smoking in bed room Odd Ratio 1.82(.95-3.49; $\mathrm{P}=0.7$ ).

Table-3:Following risk factors are related to the severe pneumonia in 2-12 months age group infants.

\begin{tabular}{llll}
\hline Risk Factor & $\begin{array}{l}\text { Odds ratio } \\
(\mathbf{9 5 \%} \mathbf{C I})\end{array}$ & P value & Wald statistics \\
\hline Malnutrition & $\begin{array}{l}6.95 \\
(3.59-13.44)\end{array}$ & .00 & $33.1834^{*}$ \\
Indoor Smoke & $\begin{array}{l}5.04 \\
(2.41-10.53)\end{array}$ & .00 & $18.4672^{*}$ \\
Non immunization & $\begin{array}{l}3.38 \\
(1.52-7.55)\end{array}$ & .00 & $8.8562^{*}$ \\
Poor housing & $\begin{array}{l}2.64 \\
(1.08-6.51)\end{array}$ & .00 & $16.3700^{*}$ \\
Cigarette smoking & $\begin{array}{l}1.82 \\
(.95-3.49)\end{array}$ & 0.7 & $3.2668^{* *}$ \\
in bed room & & & \\
\hline
\end{tabular}

Result multivariate logistic regression analysis of the risk factors significant at $95 \%$ confidence limit.

* Significant closely at 5\% level

** Significant closely at $7 \%$ level.
Significant risk factors (Table 4) for mortality in severe pneumonia are associated with 3rd degree malnutrition Odd Ratio 20.24; $\mathrm{p}=.026$, and congenital abnormality of heart with Downs Odd Ratio 31; $=.06$.

Table-4:Effect of risk factors in the outcome

\begin{tabular}{lccc}
\hline Risk Factors & \multicolumn{3}{c}{ Outcome } \\
\hline & $\begin{array}{c}\text { Total } \\
\text { Patient }\end{array}$ & Improved & Death \\
\hline $\begin{array}{l}\text { Malnutrition } \\
\begin{array}{l}\text { Indoor smoke } \\
\text { (wood or manure) }\end{array}\end{array} 1^{155}$ & 152 & 3 \\
Non Immunization & 71 & 143 & - \\
Poor Housing (slum) & 145 & 145 & - \\
Cigarette smoking & 128 & 128 & - \\
in bed room & & & \\
\hline
\end{tabular}

\section{Discussion}

Pneumonia in Pediatric age group population is the leading cause of mortality and morbidity result in economic loss ${ }^{10}$. Early recognition and management might prevent morbidity and mortality due to severe Pneumonia. Therefore we conducted a study centering risk factors of severe Pneumonia and outcome of severe Pneumonic cased with standard ARI case management schedule. Boys suffered from severe Pneumonia more frequently (70.8\%). Higher 
incidence of severe Pneumonia occurred among boys then girls observed in our study which was higher than figures $55-60 \%$ observed in other countries (Syria, Thailand, Argentina, Pakistan, Philippines) $)^{11,12}$. The increased percentage in our study may be due to prevalent of cultural practice of seeking medical care more frequently for boys than for girls. It was presumed that incidence of severe Pneumonia was higher in infants of young mother because young mother is most inexperienced in child care practices (BOSTID study in Columbia and Guatemala) ${ }^{11}$. But young maternal age is not associated with increase incidence rate of severe Pneumonia in our study. The rates of severe Pneumonia are not necessarily higher among children of less educated mother ${ }^{11}$. Though significantly increased rate was observed in our study to mothers who's academic status below secondary school certificate level. It may be that more educated mothers are more likely to note and/or report events of ARI/LRI earlier to physician. A significantly higher proportion of severe Pneumonic infant with 1st, 2nd, and 3rd degree of malnutrition compared with normal nutritional status was observed. Similar findings was also observed in Coastarica and Philippines ${ }^{12}$. Overcrowding and increasing birth order increase the incidence of severe Pneumonia was observed in this study. Similar observations were also found by the researchers in other developing countries like Philippines and Papua New Guinea ${ }^{12,13}$. Bio mass fuels consisting of wood and agricultural waste or manure are commonly used for cooking and heating by $30 \%$ of urban household and $90 \%$ of rural household ${ }^{14}$. Pollution of air due to bio mass fuel and indoor cigarette smoking and poor housing (inadequate ventilation) which was significantly associated with severe Pneumonia was observed in our study. Workers in the following countries (South Africa, India, Papua New Guinea and Navajo) also had similar observations ${ }^{13,14}$. Vitamin A is considered an important element in the maintenance of Epithelization of respiratory tract and pulmonary recovery process and plays role in host immune system. Study in Indonesia showed respiratory infection was two to four times more common in Vitamin A deficit child ${ }^{15}$. An intervention study also in Indonesia demonstrated reduction in mortality of $34 \%{ }^{16}$. Higher proportion of severe Pneumonia was observed among infants who didn't take Vitamin A. Both the present study and Indian study ${ }^{17}$ reported that non immunized infants were more prone to develop severe Pneumonia. Patient who came from poor family, suffered from severe Pneumonia more frequently. Similar observations were also observed at home and abroad ${ }^{18}$. This maybe attributed to delay in health seeking advice and lack of knowledge about severity of disease as well as poor economic status which generally associated with malnutrition, overcrowding, poor housing, all these factors contributes the infectious process to become more fatal. Patients who have treated initially by either a quack or homeopathic practitioner suffered from severe Pneumonia more frequently. This is consistent with the observation made by an Indian study ${ }^{19}$. Risk factors like artificial feeding, Congenital abnormality of heart with or without chromosomal abnormality, sibs suffered from ARI age 2-6 months were not significantly different between severely Pneumonic baby and well baby in our study ${ }^{10,12,20}$. In outcome study we observer WHO ARI case management schedule for severe Pneumonia was very effective ${ }^{21,22}$. Our finding reports that 3 rd degree malnutrition congenital heart disease were the significant risk factors for death in severe Pneumonic cased which were reported in others studies also $9,23,24$.

In conclusion it can be mentioned that in this study malnutrition, indoor smoke, non immunization, poor housing and smoking in bed room are important risk factors associated significantly with severe Pneumonia and fatal outcome. Death was associated with 3rd degree malnutrition. WHO management guideline for severe Pneumonia is very effective observed in this study. Based on this study immunization, early introduction of semi solid food, promotion of breast feeding, improvement of housing and overall improvement of economic condition are important steps for preventing severe Pneumonia. As our observation highlights the importance of indoor smoke as risk factor for severe Pneumonia, further studies are needed to elicit relationship between cooking with bio fuels and severe Pneumonia.

\section{References}

1. UNICEF/WHO, Pneumonia: the forgotten Killer of children, 2006;4-5

2. Mulholland K: Global burden of acute respiratory infections in children: implications for interventions. PediatrPulmonol 2003,36:469-474.

3. Rudan, Igor, Lana Tomaskovic, Cynthia Boschi-Pinto and Harry Campbell, on behalf of the Child Health Epidemiology Reference Group, 'Global estimates of the incidence of clinical pneumonia among children under five years of age', Bulletin of the World Health Organization, 2004;82:895-903.

4. UNICEF. The State of World,s Children. 2012:86-107

5. Statistical Pocket book, Bangladesh 2005. Bangladesh Bureau of statistics. Published in 2007.

6. Robert EB, Saul SM, jenifer B. Where and why are 10 million children dying every year. The Lancet 2003 28;361:2226-2234.

7. Mathers CD, Stein C. Fat DM. Global burden of disease 2000: Version 2, methods \& results. http: www.who.int/evidence (accessed March 14, 2003)

8. Bangladesh Demographic and Health Survey (BDHS). (Preliminary Report), National Institute of Population Research and Training (NIPORT), Mitra and Associated and Macro International Inc. Dhaka 2004.

9. Rashid KM, Rahman M, Hyder. Textbook of Community Medicine and Public Health. 4th ed. Dhaka, RHM 2004:350-353

10. Suwamjutha $S$, Ruangkanchanasetr $S$, Shnatarojanasiri T. Risk Factors associated with mobidity and mortality of Pneumonia in Thai children less than 5 years. Southeast Asian J Trop Med Public Health 1994;25:60-66 
11. Bashour HN, Webber RH, Marshall TF. A Community based study of acute reparatory infections among pre school children in Syria. Journal of Tropical Pediatrics. 1994;40:207-213.

12. Selwyn BJ, The epidemiology of acute respiratory tract infection in young children: Comparison of findings from several developing countries. Reviews of infectious Disease 1990;12:870-888.

13. Berman S. Epidemiology of acute respiratory infections in children of developing countries. Review of Infections Diseases 1991;13:454-462

14. Tupasi TE, Velmonte MA, Sanvictores MEG. Determinants of morbidity and mortality due to acute respiratory infections, implication for intervention. J Infect Dis 1988;157:615-625

15. Koning AW. Rural energy utilization and health of children. Document TRI/ARI/TAG ii/85.26. Geneva: World Health Organization, 1985.

16. Sommer A, Katz J, Tarwotjo J. Increased risk of respiratory disease \& diarrhea in children with preexisting mild Vit. A deficiency. Am J ClinNutr 1984;40:1090-1095

17. Sommer A, Tarqotjo J, Djunacdi E. Impact of Vitamin A Supplementation on childhood mortality; a randomized controlled community trial. The Lancet 1986;1:1169-1173
18. Shah N, Ramankutty V, Premila PG. Risk factors for severe Pneumonia in children in south kerala: A hospital-based case control study. Journal of Tropical Pediatrics. 1994;40:201-206

19. Vathanophas L, Sangchi R, Raktham S. A community based study of acute respiratory tract infection in Thai Children. Rev Infect Dis 1990;8:957-965

20. Victora CG, Fuchs SC, Antonio J. Risk factors for Pneumonia among children in a Brazilian metropolitan area. Pediatrics 1994;93:977-985

21. Antibiotics in the treatment of acute respiratory infection in young children. Program for the control of acute respiratory infections. WHO/ARI/90.10.

22. WHO. Acute respiratory infections in children: case management in small hospital in developing countries. WHO/ARI/90.5. Geneva: WHO,1990.

23. Deivanayagam N, Nedunchelian K, Ramasamy S. Risk factors for fatal pneumonia: A case control study. Indian pediatrics 1992;29:1529-1532.

24. Carballal G, Simonovich M, Murtagh P. Etiologic, clinical and pathologic analysis of 31 fatal cases of acute respiratory tract infection in Argentinean children under 5 years of age. Rev infect Dis 1990;12:1074-1080 